This item was submitted to Loughborough's Research Repository by the author.

Items in Figshare are protected by copyright, with all rights reserved, unless otherwise indicated.

\title{
Facilitators and barriers to the protection and promotion of the health and safety of older workers
}

PLEASE CITE THE PUBLISHED VERSION

http://dx.doi.org/10.1080/14773996.2017.1289453

PUBLISHER

(C) Taylor and Frances

\section{VERSION}

AM (Accepted Manuscript)

\section{PUBLISHER STATEMENT}

This work is made available according to the conditions of the Creative Commons Attribution-NonCommercialNoDerivatives 4.0 International (CC BY-NC-ND 4.0) licence. Full details of this licence are available at: https://creativecommons.org/licenses/by-nc-nd/4.0/

\section{LICENCE}

CC BY-NC-ND 4.0

\section{REPOSITORY RECORD}

Drake, Carolyn, Roger Haslam, and Cheryl Haslam. 2019. "Facilitators and Barriers to the Protection and Promotion of the Health and Safety of Older Workers". figshare. https://hdl.handle.net/2134/26031. 
Facilitators and barriers to the protection and promotion of the health and safety of older workers

Carolyn Drake ${ }^{\mathrm{a}}$, Roger Haslam ${ }^{\mathrm{a}}$ and Cheryl Haslam ${ }^{\mathrm{b}}$

Loughborough Design School, Loughborough University, Loughborough, Leicestershire, UK

School of Sport, Exercise and Health Sciences, Loughborough University, Loughborough, Leicestershire, UK

Correspondence:

Carolyn Drake

c.m.drake@lboro.ac.uk

Loughborough Design School, Loughborough University, Loughborough, Leicestershire LE113TU, UK 


\begin{abstract}
Individuals may experience health issues or physical, sensory or psychological capability changes related to ageing. With the removal of the default retirement age in the UK, older workers can remain in work well into later life. Health and safety statistics, however, indicate that they are a vulnerable group. Older workers have much to contribute, but employers have a responsibility to examine the working environment to protect those with reduced capabilities. This article reviews two qualitative studies examining the facilitators and barriers to implementing age management strategies to promote the health and safety of older workers. The findings reveal that employers are uncertain how to proceed with implementing actions to protect older workers. Discussions with older workers reveal they do not feel sup- ported or engaged. They are fearful of reporting any capability changes that may affect their ability to perform work tasks as they believe this may have negative consequences for their future employment. A co-ordinated multi-disciplinary approach between human resources, operational management, health and safety specialists and occupational health functions is required. Two qualitative studies review the barriers and facilitators to the implementation of age management strategies to promote the health and safety of older workers. Findings show that a multidisciplinary approach between human resources, operational management, safety and health specialists is required.
\end{abstract}


Practitioner summary: Two qualitative studies review the barriers and facilitators to the implementation of age management strategies to promote the health and safety of older workers. Findings show that a multidisciplinary approach between human resources, operational management, safety and health specialists is required.

Keywords: occupational health and safety, ageing and older worker, employer support, age related capabilities

\section{Introduction}

According to The World Health Organisation (WHO 2015a) the world population is ageing rapidly, due to an increase in life expectancy and declining birth rates. Latest estimates are that between 2015 and 2050 the proportion of people over 60 years of age worldwide will almost double. While this demographic shift started in high-income countries, it is the low and middle income nations that are now experiencing the highest rate of change e.g. China and India (WHO 2015a). In the United Kingdom the latest statistics showed $35 \%$ of the population were over 50 years of age and this is projected to increase to $42 \%$ by 2050 (ONS 2015a). The UK government uses this information 'to inform policy regarding state pension' (ONS 2015b). As a result of the pressure on state pensions, the UK government has already increased the default pension age and removed the mandatory retirement age.

When considering an ageing workforce it is relevant to understand the extent of occupational injuries. In the United States the highest risk age group for fatalities is over 65 year olds, and for non-fatal injuries it is the 45 to 54 year age group, followed 
closely by the 55 to 64 year old age group (Bureau of Labor 2016). In the UK, RIDDOR statistics show that workers over 65 years are more at risk of fatal accidents (HSE 2016a). In both the RIDDOR non-fatal specified injury category and the over 7-day injury category, the highest incident rate was for 60 to 64 year olds. Data also show that older workers have longer recovery times when involved in an accident (Ross 2010). The World Health Organisation (WHO 2015b) has devised a global strategy and action plan looking to foster 'healthy ageing' built around ‘functional ability’ enabling older people to continue participating in society. With an increase in the overall age of the workforce, employers face both health and safety challenges as well as opportunities. Unless employers examine the consequences of their ageing workforce and respond appropriately they may face increased injuries and reduced productivity.

In the literature, the definition of an 'older worker’ varies. While some researchers classify this age group commencing at 45 years old, many researchers have chosen to use 50 years as a threshold. However due to the individual variability of age related capability changes resulting from a range of contributing factors, chronological age may not be a reliable indicator of health and functional ability (Kowalski-Trakofler et al 2005, Crawford et al 2010).

For the purposes of this research an older worker is classified as over 50 years of age, in line with other studies (e.g. Loretto and White 2006, Okunribido and Wynn 2010, Haslam et al 2013). In 2014 the UK government appointed a champion specifically to support over-50s in the UK labour market (Gov.uk 2014a). Ilmarinen (2001) and Costa et al (2011) believe an early age definition enables possibilities for occupational health and safety preventative measures to be implemented to help with any changing capabilities before ill health or injury occurs. 


\section{Age related changes}

As individuals age, they experience natural age related changes in capabilities, physical, sensory or psychological. Older people can also suffer from specific age related health problems.

\section{Physical}

Studies have identified that body composition tends to change with age with increased weight and reduction in height (Crawford et al 2010, Schwatka et al 2012). Motor movements are particularly susceptible to age related changes i.e walking, bending, twisting, grasping, along with a reduction in flexibility, mobility, decline in balance and posture (Kowalski-Trakofler et al 2005, Silverstein 2008). Strength can also decline with age (Kowalski-Trafofler et al 2005).

\section{Sensory}

Vision changes with age, with potential declines noted in depth perception and loss of colour and contrast sensitivity (Kowalski-Trakofler et al 2005, Silverstein 2008). It has also been noted that people over 55 years old require increased lighting compared to a person under 40 years old and they may also be more susceptible to glare (KowalskiTrakofler et al 2005, Boyce 2008). Age is also known to be a risk factor for hearing loss, which at the age of 60 years could be as much as $25 \mathrm{~dB}$ loss; the loss is less pronounced in women (Perry 2010, Farrow \& Reynolds 2012). A loss of high frequency tones, difficulty in understanding distorted speech and possible sensitivity to loud noise has also been noted (Kowalski-Trakofler et al 2005). 


\section{Psychological}

Researchers have noted reductions in reaction time and cognitive processing as individuals age. Psychologists distinguish between memory processing functions, with 'fluid' functions requiring immediate processing and 'crystallized' functions requiring processing based on previous knowledge, the latter being preserved with age (Silverstein 2008).

\section{Health conditions}

Older people can suffer from specific age related health problems e.g. degenerative joint disease, cardiovascular disease, osteoporosis. It has been noted that arthritis (joint inflammation) can significantly increase in over 45 year olds. Differences exist between men and women, with women as they age being more susceptible to certain conditions, such as arthritis and osteoporosis (Kowalski-Trakofler et al 2005). Changes to weight and body composition may also predispose some individuals to diabetes and hypertension (Schwatka et al 2012).

\section{The impact of age related changes within the work environment}

Musculoskeletal issues represent a significant challenge for older workers and employers, often compounded by workers’ longer exposure over their working career (Crawford et al 2010). This affects older workers’ ability to complete work tasks and maintain performance. With the possible decline in balance and posture there could also be an increased risk of slips, trips and falls (Silverstein 2008), although precise patterns of this are unclear (Bentley and Haslam 1998, Chang et al 2016). With decline in strength and joint mobility, employers need to be aware of potential muscle fatigue in the older worker. Potentially hazardous are tasks requiring high muscular force i.e lifting, pushing, pulling and carrying (Kowalski-Trakofler et al 2005). Older workers in 
general may work closer to their physical limits (Silverstein 2008). Some roles may place significant challenges on older workers, due to both the physical demands of the job and the daily working environment i.e harsh weather, irregular hours, awkward positions, heavy lifting or handling vibrating equipment (Schwatka et al 2012). Studies have also identified a requirement for increased recovery time for older employees working more than 42 hours per week (Crawford et al 2010).

Due to changes in vision, if work is conducted where lighting problems may be experienced e.g. at workstations or driving work tasks during darker hours, the visual element of the task should be assessed (Boyce 2008, Beers \& Butler 2012). Age induced hearing loss will be a factor for those communicating in noisy environments, those requiring to hear accurate verbal instructions as well as any audible systems (Perry 2010). Older workers with hearing loss may find the communication demands lead to mental exhaustion which could pose a safety risk (Jennings et al 2010).

With the rise in the service sector and decline in manufacturing in some countries, the traditional routinised approach, with work segmented into individual tasks has been replaced by job flexibility requiring constant adaptation. This can result in older workers leaving their jobs rather than having to adapt to significant changes within the organisation (Yeatts et al 2000). With the decline in physically demanding jobs, older workers may have improved employment prospects (Johnson et al 2011), however contemporary work has become increasingly sedentary, which represents a health risk for employees and challenge for employers (Boyce 2008, Kazi et al 2014). Where cognitive decline occurs, individuals may compensate with their increased experience and job knowledge (Crawford et al 2010, HSE 2016b). An example of this was noted in the aviation sector regarding air traffic controllers and pilots where cognitive processing speed and multitasking declined with age, but 
experience mitigated any decrease in performance (Beers \& Butler 2012). However Choi (2008) noted that older construction workers were less likely to respond quickly to distress conditions as work situations changed. Duke et al (2010) conducted research on age-related safety in professional heavy vehicle drivers and found that reaction times could be impaired by fatigue, a leading contributor to collisions. This research observed increased rates of accidents in drivers over 63 years of age, with increased risk during night-time driving.

Work scheduling can also have an impact on health of older workers (Volkoff et al 2010). Research examining the effects of shift work has found that increasing intolerance to night work is noticed between the ages of 40 and 50 years (Costa \& Sartori 2007, Boyce 2008). This work pattern interferes with circadian rhythms and can lead to errors and accidents, as well as exacerbating longer term health disorders. Harma (1996) recommended that night work should be voluntary after 40 years of age.

Work ability was first defined in the early 1980s in Finland in relation to an individuals’ ability to meet the physical, social and mental demands of a particular job (Ilmarinen et al 2005). Ageing is a continuous process and work ability is only maintained when appropriate interventions are implemented in response to this (Kowalski-Trakofler et al 2005, Bohle et al 2010). Ergonomics approaches can improve the design of the work environment, tools, tasks and fit these to the worker (Kowalski-Trakofler et al 2005). Products and environments should be of 'universal design' meeting the requirements of all age groups, thus not only creating an agefriendly workplace but also preventing or slowing potential work related declines in younger workers as they age (Silverstein 2010). However Streb et al (2008) raise concerns that many workplaces are still being designed for physically fit younger workers. 
There is also a requirement in effective training for older workers, increasing the likelihood that they will re-establish an acceptable person - job fit following work changes (Yeatts et al 2000). However, with the increase in jobs requiring cognitive skills that need to be updated regularly, older workers could be disadvantaged as some employers are reluctant to invest in training as they believe they will be unable to recoup the costs (Johnson et al 2011). The European Commission (2011) conducted a survey 'Active Ageing' to understand the perceptions of age and the older person. It found that employees over 55 years were perceived to be reliable and experienced, but less open to new ideas, had less knowledge about new technology and were excluded or less willing to attend training. The HSE (2016b) believe this stereotype is damaging. Kooji et al (2008) argue that negative views can impact on an older workers' motivation to continue working. Ng \& Feldman (2008) found that older workers demonstrate greater safety-related behaviour and have less voluntary absence. Extensive research undertaken in the automotive sector revealed that team performance improved when the average age of employees increased (Streb \& Gellert 2011). In research conducted by Haslam et al (2013) their results demonstrated that employers see the benefits of retaining older workers thereby maintaining essential skills and knowledge within the organisation.

Within this context, the aim of the research presented in this paper was to understand the facilitators and barriers to the implementation of age management strategies to protect and promote the health and safety of older workers.

\section{Method}

This paper discusses the findings from two studies, the first involved interviews with employers and the second conducted employee focus groups. The research adhered to 
the requirements of Loughborough University ethical advisory committee. Following each study the data were transcribed and then transferred into qualitative data analysis software NVIVO (version 10). As the interviews were coded, themes and patterns were identified in response to the frequency of answers to key questions (Thematic Analysis) (Braun \& Clarke 2006). During the thematic analysis both deductive and inductive coding was used (Bryman 2012). The reliability of the analysis was ensured by having a second independent researcher check a sub sample of the data and the analysis.

\section{Interview study: understanding employers' perspectives regarding health and safety and older workers}

Specific aims of the interviews with UK employers were to understand their perception of the benefits older workers bring to their organisation, any implications or concerns regarding an ageing workforce, how they transfer health and safety knowledge and what health and safety age management strategies they had implemented.

Senior personnel $(\mathrm{n}=41)$ influencing health and safety management strategies (e.g. design, development, implementation) were interviewed. Interviewees were invited from different size organisations across 13 sectors in the UK (see table 1). For this research organisation size is classified according to number of persons employed (Eurostat 2014): Small - 10 to 49 persons employed, Medium - 50 to 249 persons employed, Large - 250 or more persons employed.

Participants were recruited as a convenience sample by contacting local organisations and using snowball sampling (Bryman 2012). Participants were also recruited through organisations offering to help with this study following a request placed in the Safety and Health Practitioner magazine (May 2014 edition) and via Linkedin specialist groups 
(CIEHF specialist group for Ageing, Work and Health and Safety Professionals UK Group). The interviews were conducted either face-to-face $(n=11)$ or via telephone $(n=30)$.

\section{Employee focus groups: understanding older workers' perspectives regarding health and safety}

Focus groups were the preferred method for this second study stage in order to elicit a wide range of responses regarding the experience of older workers concerning their health and safety and approaches to this by employers. The specific aims of the focus groups were to understand their views on health and safety adjustments implemented and support offered, their views on their organisations' health and safety reporting culture for age related capability changes, age awareness training, how they share their health and safety knowledge and if they had any suggestions to help older workers remain in the workplace.

Prompt questions were used to provoke group discussion with 10 focus groups. Target participants for this study were any workers over the age of 50 years. Apart from the pilot focus group, which consisted of academics and operatives in physical roles, all the focus groups were conducted within the manufacturing sector using convenience sampling. The organisations taking part recruited and allocated the participants into focus groups containing either managers/office personnel or operatives (see table 2).

\section{Results}

\section{Employer perceptions of older workers}

During the interview study all employer respondents stated that older workers bring 
health and safety benefits to the workplace. The key benefits commented on by over two thirds of respondents was older workers' experience and knowledge. Another benefit cited was their 'common sense'. Older workers bring a stability and maturity that produces a more cautious attitude, resulting in being less likely to react to changing situations too quickly, without giving consideration to the consequences. Due to this experience and knowledge the respondents felt that older workers understand the 'bigger picture' and are able to anticipate problems and correct them in a timely manner; some of this being the result of their experiences and knowledge of previous incidents.

'They have many stories to tell about their past experiences and know the consequences of certain actions. Their perception is a little bit more real because they have worked in high hazardous environments in the past' (Operations Manager, Manufacturing).

However half of the employers interviewed also stated negative opinions about some of their older employees, finding them reluctant to change and unhelpful.

'It depends on their attitude and tenure. For example, if they have moved to another site they can be more enthusiastic. However others can be cynical depending on their business knowledge age. They can be blockers to ideas and say things have already been tried and why try to change things, so they are hardier to convince as they have seen a lot of things fail in the past' (Head of Standards and Governance (HSE), Wholesale and Retail).

Experience was also construed negatively with employers witnessing established bad habits being passed on to younger employees and older workers taking short cuts instead of following the rules. 
During the interviews employers were asked if they had any health and safety concerns regarding their older workers. Ninety-three percent $(n=38)$ of the employers cited concerns. The greatest concern regarded changes in physical capabilities, other concerns were reduced cognitive capabilities, shift work, fatigue, age-related health issues and driving. Higher absenteeism and a decline in performance were also cited as possible consequences of an ageing workforce. Seventy-one percent $(n=29)$ of employers said their organisation had experienced employees over 50 years old taking early retirement within the last two years due to their inability to carry on within their current job role. For some organisations redeployment had been an option in the past due to the relatively low numbers involved and finite working period, however comments were made that in the future this may prove difficult if the numbers of people requiring alternative work increases as there are now fewer redeployment options available.

\section{Health and safety actions responding to an ageing workforce}

Employers were asked if they had implemented any health and safety actions to help protect their older workers. The following responses were provided:

- Completed actions already $44 \%(n=18)$

- Have plans that are expected to be implemented within the next 12 months $10 \%$ $(n=4)$

- Currently having discussions on how to proceed $5 \%(n=2)$

- No plans $41 \%(n=17)$

The organisations that had already completed actions were asked what they had implemented, with the following responses:

- Introduced additional health surveillance as workers age (mainly for those in 
specific roles)

- Additional risk assessments completed based on role and capability

- Flexible working hours

- Introduced behavioural safety programme using observations

- Introduced an age limit on specific tasks

- Enhanced supervisor observations

- Introduced personal development/self-analysis courses

Of the employers that responded that they currently have no plans to implement additional control measures some stated that they were relying on existing health surveillance (provided for specific roles) to identify any problems or highlight new requirements.

'We need to be more proactive, with stronger awareness and monitor people's performance. We tend to take the older worker for granted that they are capable and dependable...' (Health and Safety Manager, Manufacturing).

Various comments were received suggesting that organisations were unsure how to handle their ageing workforce should they experience capability changes.

'I'm not sure how some workers with physical jobs are going to continue working past 60 years old, I'm not sure what is going to happen to them' (Health and Safety Advisor, Manufacturing).

'The business is squeezed for producing good numbers and we can't afford to carry dead wood when you have to reach a certain turnover per hour per employee’ (Operations Manager, Retail). 


\section{Reporting culture and hidden health problems}

Employers were asked if they believed there would be implications for their organisation as their workforce aged. An ineffective reporting culture within the organisation received the most responses to this question (two-thirds). Respondents believed that employees were not always volunteering information about potential problems they may be experiencing due to fear of the consequences. Another potential problem highlighted was the lack of knowledge surrounding employees who take medication, which may have side-effects that could potentially impact on the health and safety of the employee. Some respondents believed that employees hidden health issues could potentially increase risk to other employees.

'People still think it will be frowned upon if you admit you are having problems, especially if it's something that is not going to get better but related to age decline’ (Group Health and Safety Manager, Arts \& Entertainment).

In the majority of situations there is a reliance on line managers to identify problems, however this also raises a further challenge as employer interviews indicated that line managers did not receive training on age awareness.

Discussions with focus groups aligned with the employers' belief that fear of consequences is prohibiting older workers from reporting problems. Some participants cited previous experiences as the basis for their opinion. People they knew who had reported capability changes had been either 'sacked' or made redundant. Some of the focus group participants discussed that they did not trust their manager, saying any conversation they may have with their manager would not be kept confidential and they might then be subjected to ridicule by colleagues. One participant said they had informed their manager about a degenerative knee problem, which was then used by the manager as a reason for not considering their application for promotion. Loss of dignity 
and lack of respect from younger managers were also mentioned as a reason for not reporting capability changes that may impact on work.

'Yes I often think come on mate I've been there, done that. Don't talk to me like that. I've seen it with my mate I work with, he's 63 and I see how bad the younger line managers talk to him. He is probably the longest serving guy here but there is no respect. That culture has to change' (Focus group 8).

Many focus group participants were unsure about what adjustments the organisation could put in place if an employee's capabilities changed. Participants believed it would be beneficial for everyone to know how people would be treated, but some believed that their organisation would not treat everyone the same. When the participants were asked if they were aware of any actions their company had taken some of those mentioned were constructive to help the older workers remain in the workforce, while some were negative with people being 'sacked'. When discussing actions about capability changes some participants tried to manage their own adjustments. Two participants had already considered their future working career and had decided to change jobs as they felt they would not be able to continue in their present role.

\section{Discrimination and guidance}

Nearly a third of employers indicated their organisation was unsure how to proceed with implementing an age management strategy as it may be viewed as age discriminatory. Some explained that they were reliant on the occupational health function in the organisation.

'Occupational Health is going to be key... As a business we know we have an ageing workforce with lots of guys having worked here for $20+$ years. We consider them within the normal occupational health regime but we don't really 
consider it from an age point of view and spotting declines... We are not doing anything extra as people age. People are shying away from it possibly because they are not sure what needs doing or possibly because it may be seen as discrimination’ (Head of Health and Safety, Manufacturing).

While respondents acknowledged the importance of keeping people safe, some employers in specific health and safety roles said when they tried to be proactive and implement age management strategies they found the Human Resources department were blocking suggestions citing discrimination, but were offering no guidance, so initiatives tended to be reactive.

'Employers have a problem tackling this, as it’s possibly seen as discriminatory and they don't really know what to do. It will be interesting to see what HSE do. HSE changing or adding to legislation would help give employers some foundation to move forward and include this alongside young workers, pregnant workers, disabled etc' (Health and Safety Manager, Human Health and Social Work).

When focus groups were asked if they believed it would be fair to implement adjustments for older workers, there was agreement that adjustments would be fair and should be implemented proactively to help all older workers.

'Growing old is something you shouldn't be ashamed of and if there any changes that can be facilitated and help then I think that's fantastic to extent your working life’ (Focus group 10).

Participants in the focus groups believed this would help to deliver consistent support and would be beneficial as this would pick up problems someone may be experiencing but would otherwise not report. However one participant then said it would be too 
formulaic and did not take account of the capability variation of employees, while another said there could be problems implementing adjustments within a working environment where everyone was of a similar age.

\section{Age awareness training}

As mentioned above when employer interviewees were asked if their organisation provided any age awareness training nearly all respondents responded that they did not. Of those employers who did provide some form of age awareness training they were either in the health care sector or their managers could request the training but this generally only happened if they experienced 'absence issues' amongst their staff. One organisation offered voluntary training to any interested employees, but only as part of retirement planning.

During the focus groups there was agreement that all managers/supervisors should receive such training.

'It should be about having managers well trained in this kind of thing, to be aware of it and if necessary feel as though they can put measures in place to maybe alter the pattern of work that person does so that the work doesn't hamper the persons health and their output' (Focus group 5).

Participants felt it could help provide better continuity of support and help younger managers understand and be more sympathetic when older workers experienced age related issues. The focus groups were then asked if they thought this training should be provided for all employees. Participants believed training would help allay fears about capability changes and would hopefully provide knowledge regarding potential measures organisations could pursue if someone's capability declined. Two groups of participants felt quite strongly that age awareness training should include dementia and 
Alzheimers disease. One participant cautioned that following the training some people may request adjustments whether they were required or not.

\section{Succession planning and knowledge transfer}

Employer interviewees stated that succession planning was a potential problem. Some thought younger workers may sometimes perceive older workers as 'blockers' to their promotion prospects. Another problem raised was notice periods, in some of the organisations those planning to retire only had to give one month's notice, thus making it difficult to fill technical roles at such short notice. Employers from both manufacturing and retail were having problems recruiting as younger workers were not interested in their sector as the pay was lower and younger workers were not interested in 'learning the trade'.

When employer interviewees were asked if they captured health and safety knowledge responses varied significantly. Over a third of organisations represented had no formal processes in place to capture knowledge and relied on informal knowledge sharing only. All of the focus groups agreed that informal knowledge sharing took place. Employer interviewees acknowledged that this left organisations unsure as to what information had been disseminated, diluted and lost over time. Some representatives said that their organisation used experienced mentors/coaches to pass on knowledge, or used their experienced employees to assist in developing safe systems of work and risk assessments. Others said their organisation arranged various meetings, tool box talks, training sessions where employees discussed their experiences and one interviewee said there was a library where information was registered. Some organisations arranged formal handover sessions and one organisation used retired employees on an ad hoc basis to supplement their workforce. Comments during the 
focus group discussions also made reference to lack of succession planning so health and safety knowledge was lost when older workers retired. During these discussions, an organisation's headcount was provided as a reason why some organisations may be reluctant to employ a successor before someone had retired.

'There seems to be a problem with the terminology of 'headcount'... when you know someone is leaving you increase your workforce early giving them chance to train and learn the job, they naturally filter into the system. But when the company is focused only on headcount you can’t employ a successor early and that puts a strain on the existing workforce, as well as all that knowledge being lost' (Focus group 3).

\section{Worker suggestions}

The focus groups were asked if they had any suggestions that employers could implement that may help retain older workers and keep them healthy and safe in the workplace. Workers had many suggestions (see table 3).

\section{Discussion}

The combination of interviews with employer representatives and focus groups with workers has provided new knowledge on the readiness of organisations to support health and safety of the older workers and the issues involved. At a broad level, the findings indicate many organisations are unsure how to proceed. Employees expressed concerns about their treatment. The following sections summarise the policy and practice implications of the findings. 


\section{Importance of an age management strategy}

Although older workers can compensate for some age related decline in their capabilities, it is important that employers have management strategies in place to protect this group of workers from increased risks to their health and safety. Variation in individual capabilities widens with age, rendering chronological age an unreliable indicator of functional ability. During interviews some participants proposed the introduction of age-limits to certain jobs/tasks which suggests that this message needs to be made clearer to employers. As Streb et al (2008) stated “older workers seem to be sufficiently flexible and willing to be as productive as their relatively younger colleagues”, however this will only be achieved by organisations providing a safe environment and implementing relevant measures.

When discussing possible implications of an ageing workforce with employers, some commented about the additional financial cost that their organisations may experience due to 'keeping people on the books’ with high absenteeism or loosing contracts due to reduced productivity. Cost implications regarding training investment was also discussed. This is consistent with research conducted by Johnson et al (2011) who suggested employers are reluctant to invest in training as they will be unable to recoup the costs. This view is consistent with Streb et al (2008) who noted that organisations may experience significant cost burdens due to absenteeism and the potential increased numbers of employees who may need adjustments or have constraints placed on their performance. There is no 'one size fits all' strategy as different sectors face different challenges (Silverstein 2008). It is important that job demands, work environments and capability requirements are assessed, so that employers have an understanding of which tasks have no age issues and those that could be a problem (Ziekemeyer 2005). 


\section{Occupational health function}

The analysis of the results shows that organisations are heavily reliant on Occupational Health surveillance measures to identify issues and detect capability changes. Whilst there is little doubt of the importance of Occupational Health, comments were predominantly focused on reactive Occupational Health (return to work) and periodic health surveillance. When discussing health surveillance with the participants in this study it was clear that the surveillance intervals varied greatly and within some organisations not all employees were selected to receive health checks. Early diagnosis of issues would be valuable for organisations and probably welcome, as Crawford et al (2010) noted in their research that older workers see positive benefits of health checks.

\section{Reporting culture}

Concerns over workers reporting problems featured in both the employer interviews and employee focus groups. Some of the comments as to why employees were unwilling to declare changing capabilities was related to 'fear of consequences'. Employers discussed their concern that employees were 'hiding' their problems, with colleagues 'covering for them', which inadvertently put everyone at risk. If managers are not identifying problems they will be unable to identify specific risk factors and risk groups and so will be unable to implement necessary interventions (Hoonakker \& van Duivenbooden 2010, Popkin et al 2008). Some of the focus group participants also said that some employees do not report issues because they do not trust their manager, with lack of confidentiality cited as one reason for mistrust. Clarke (2003) believes that mutual trust is necessary to create a positive safety culture. With a high number of participants stating that the reporting culture in their organisation is poor, reliance on employees volunteering information may be ineffective. 


\section{Age awareness training}

When employers were asked if they provided any specific age related training, a high percentage said no. Placing responsibility on managers to notice potential issues could be problematic, as it was identified that they are not provided with the necessary knowledge and tools to recognise and address changing capabilities. Focus group participants felt that it would be beneficial for everyone to receive age awareness training, not only managers. It was noted that the training would improve reporting as people would understand the policy and their options as their capabilities may change. In some instances training may also help individuals manage their own minor capability changes or help them assess their current role to decide if they believe it may be possible to continue in that role until retirement.

\section{Discrimination}

There are various reasons why organisations are relying on the Occupational Health function, but one reason stated by nearly a third of employer interviewees was that they were unsure how to proceed with implementing age management strategy as it may be viewed as discriminatory. This is consistent with Silverstein (2008) who stated that employers are fearful of being considered discriminatory so have been slow to meet the needs of older workers. 'Age discrimination is unfairly treating people differently because of their age’ (Gov.uk 2014b). Under the Equality Act (Gov.uk 2014b) a legitimate aim might include health, safety and welfare protection of older workers and the HSE (2016a) state that it can be justifiable to discriminate in respect to age if it is proportionate to achieve a legitimate aim i.e changes to a workplace required to ensure older workers are safe and can remain in work. It would seem that employers have yet to be reassured about this. 


\section{Adjustment implementation}

Employees in the focus groups commented that they believed it was fair that adjustments were implemented. When participants were asked when would be an appropriate time to implement measures, most said that measures should be implemented proactively for all older workers. This would help circumvent the problem of workers not reporting potential health and safety issues until it is too late to help and would also assist those who may not want to admit they are experiencing capability changes or have not recognised they are experiencing changes.

\section{Support}

During the discussions a theme that was frequently mentioned was inconsistent support provided for older workers. Suggestions offered by focus group participants to help older workers remain in the workplace in a healthy and safe manner placed fair and consistent treatment of older workers at the top of their list. It is apparent that 'age management' and 'age awareness' fall into both Health and Safety and a Human Resources remit and there needs to be better coordination as they proceed.

\section{Succession planning and knowledge transfer}

For many organisations succession planning was problematic. Previously organisations kept personnel records showing a retirement date when it was expected people would need to be replaced and as ACAS (2006) suggested analysing this information allowed for planning and action at peak retirement times. New recruits could be employed and receive health and safety training before older employees left the organisation. Now organisations are finding succession planning challenging as employees are either opting to provide a date when they may retire, but then choosing not to leave their 
employment, or they are confirming their intention to leave, but only giving a short notice period. This causes organisations problems, not only in the timely recruitment and health and safety training of new employees, but also in trying to transfer relevant health and safety knowledge. Some focus group participants felt their organisation was detrimentally pre-occupied with a headcount target, when it would be more effective to be proactive with succession planning. This was believed to have an adverse effect on personnel and operations. Comments were given that recruitment was being left too late and this was having a detrimental effect on remaining employees who were experiencing additional pressure finding extra time to train successors. It is important that organisations safeguard against the threat of loss of knowledge especially if large cohorts of older workers retire (Streb et al 2008).

\section{Limitations of studies and conclusions}

The employer interview study required that the target respondent should be able to influence health and safety management strategies. However, some of the employer interviewees did not possess all the required knowledge to answer all the questions. Some of the health and safety professionals were not always involved with capability issues, which were viewed as a Human Resources/Occupational Health area. Therefore, whilst some reported data accurately, others were only able to provide estimates.

The sample was also skewed towards the manufacturing sector and larger organisations (250+ employees). This may limit the generalised findings, however the findings certainly allow for further exploration to be identified. Due to the number of participants required for each focus group and the duration of a group, only medium and larger manufacturing organisations were able to meet the required criteria. Another factor was the high male dominance of the gender split of focus group participants, with 
only $13 \%(n=6)$ of the participants being female. These focus group limitations may limit the generalised findings.

In summary, it would appear that many employers are dealing with ageing workforce issues on a reactive basis, whereas it is argued that these problems are important enough to be considered proactively. A co-ordinated multi-disciplinary approach including human resources, operational management, health and safety and occupational health personnel is required. Employers need to include 'age' as part of their diversity policies and provide 'age awareness' training to relevant personnel in order to avoid discriminatory practices. Prevention or early diagnosis of issues should be actioned. Engagement with older workers and a co-ordinated approach will be key to the implementation of effective health and safety age management.

\section{References}

ACAS (Advisory, Conciliation and Arbitration Service), 2006. Age and the workplace. www.acas.org.uk (accessed $17^{\text {th }}$ July 2014).

Beers H, Butler C, 2012. Age related changes and safety critical work. Identification of tools and a review of the literature. Health and Safety Executive Research Report RR946.

Bentley T A, Haslam R A, 1998. Slip, trip and fall accidents occurring during the delivery of mail. Ergonomics 41, 1859-1872.

Bohle P, Pitts C, Quinlan M, 2010. Time to call it quits? The safety and health of older workers. International Journal of Health Services, 40, 23-41. 
Boyce R W, 2008. An ergonomic approach to the aging workforce utilizing this valuable resource to best advantage by integrating ergonomics, health promotion and employee assistance programs. Journal of Workplace Behavioral Health, 23, 179-199.

Braun V, Clarke V, 2006. Using thematic analysis in psychology. Qualitative Research in Psychology 3:2, 77-101.

Bryman A, 2012. Social research methods $4^{\text {th }}$ edition. Oxford University Press.

Chang W-R, Leclercq S, Lockhart T E, Haslam R, 2016. State of science : occupational slips, trips and falls on the same level. Ergonomics. Taylor and Francis Online. DOI 10.1080/00140139.2016.1157214 (accessed 25 ${ }^{\text {th }}$ August 2016).

Clarke S, 2003. The contemporary workforce : implications for organisational safety culture. Personnel Review, 32, 40-57.

Costa A F, Puga-Leal R, Nunes I L, 2011. An exploratory study of the work ability index (WAI) and its components in a group of computer workers. Work, 39, 357-367.

Crawford J, Graveling R, Cowie H, Dixon K, 2010. The health safety and health promotion needs of older workers. Occupational Medicine, 60, 184-192.

Choi S, 2008. Safety and ergonomic considerations for an ageing workforce in the US construction Industry. Work, 33, 307-315. 
Costa G, Sartori S, 2007. Ageing, working hours and work ability. Ergonomics, 50, 1914-30.

Duke J, Guest M, Boggess M, 2010. Age related safety in professional heavy vehicle drivers : a literature review. Accident Analysis and Prevention, 42, 364-371.

European Commission, 2011. Active Ageing - Special Eurobarometer 378. http://ec.europa.eu/public_opinion/archives/ebs_378_en.pdf (accessed 2nd December 2013).

Eurostat, 2014. Glossary:Enterprise size. http://ec.europa.eu/eurostat/statisticsexplained/index.php/Glossary:Enterprise_size (accessed $20^{\text {th }}$ February 2014).

Farrow A, Reynolds F, 2012. Health and safety of the older worker. Occupational Medicine, 62, 4-11.

Gov.uk, 2014a. A powerful new voice for older workers. Press release from Department for Work and Pensions. https://www.gov.uk/government/news/a-powerful-new-voicefor-older-workers (accessed 30th October 2014.

Gov.uk, 2014b. Equality Act 2010.

http://www.legislation.gov.uk/ukpga/2010/15/contents (accessed 17th July 2014).

Hansson R O, Robson S M, Limas M J, 2001. Stress and coping among older workers. Work, 17, 247-256.

Härmä M, 1996. Ageing, physical fitness and shiftwork tolerance. Applied Ergonomics, 27, 25-9. 
Haslam C, Clemes S, Crawford J, Gibb A, Gyi D, Haslam R, Maguire M, McDermott H, Morgan K, Nicolle C, 2013. Working late: strategies to enhance productive and healthy environments for the older workforce. http://www.workinglate.org/may-expertpanel/ (accessed 19 $9^{\text {th }}$ November 2013).

Hoonakker P, van Duivenbooden C, 2010. Monitoring working conditions and health of older works in Dutch construction industry. American Journal of Industrial Medicine, 53, $641-653$.

HSE, 2014. Vulnerable workers. http://www.hse.gov.uk/vulnerable-workers/olderworkers.htm.

HSE, 2016a. RIDAGEN Reported injuries to employees in Great Britain by severity of injury and age of injured person, 2010/11 - 2014/15p.

http://www.hse.gov.uk/Statistics/tables/index.htm\#riddor (accessed $7^{\text {th }}$ September 2016).

HSE, 2016b. Health and safety for older workers. http://www.hse.gov.uk/vulnerableworkers/older-workers.htm (accessed 7th September 2016).

Ilmarinen J E, 2001. Aging workers. Occupational and environmental medicine, 58, $546-52$.

Ilmarinen J, Tuomi K, Seitsamo J, 2005. New dimensions of work ability. International Congress Series, 1280, 3-7.

Jennings M B, Shaw L, Hodgins H, Kuchar D, Bataghva L P F, 2010. Evaluating auditory perception and communication demands required to carry out work tasks and 
complimentary hearing resources and skills for older workers with hearing loss. Work, 35, 101-13.

Johnson R, Mermin G, Resseger M, 2011. Job demands and work ability at older ages. Journal of Aging and Social Policy, 23, 101-118.

Kazi A D M, Clemes S, Haslam C, 2014. A survey of sitting time among UK employees. Occupational Medicine 64, 497-502.

Kooij D, Lange A, De Jansen P, Dikkers J, 2008. Older workers’ motivation to continue to work: five meanings of age: A conceptual review. Journal of Managerial Psychology, 23, 364-394.

Kowalski-Trakofler K M, Steiner L J, Schwerha D J, 2005. Safety considerations for the aging workforce. Safety Science, 43, 779-793.

Loretto W, White P, 2006. Employers' attitudes, practices and policies towards older workers. Human Resource Management Journal, 16 (3).

Ng T W H, Feldman D C, 2008. The relationship of age to ten dimensions of job performance. Journal of Applied Psychology, 92, 392-423.

Okunribido O, Wynn T, 2010. Ageing and work-related musculoskeletal disorders. Health and Safety Executive Research Report RR799.

ONS, 2015a. Population projections. http://www.ons.gov.uk/ons/dcp/171778420462.pdf (accessed 9th December 2015). 
ONS, 2015b. Births, deaths and marriages/life expectancy.

http://www.ons.gov.uk/peoplepopulationandcommunity/birthsdeathsandmarriages/lifee xpectancies/bulletins/pastandprojecteddatafromtheperiodandcohortlifetables/2014based uk1981to2064 (accessed 9th September 2015).

Perry L S, 2010. The Aging Workforce - Using ergonomics to improve workplace design. Professional Safety, April 2010, 22-28.

Popkin S, Morrow S, Di Domenico T, Howarth H, 2008. Age is more than just a number. Implications for an aging workforce in the US transportation sector. Applied Ergonomics, 39, 542-549.

Ross D, 2010. Ageing and work : an overview. Occupational Medicine, 60, 169-171.

Schwatka N V, Butler L M, Rosecrance J R, 2012. An aging workforce and injury in the construction industry. Epidemiologic Reviews, 34, 156-67.

Silverstein M, 2008. Meeting the challenges of an aging workforce. American Journal of Industrial Medicine, 51, 269-280.

Streb C, Voelpel S, Leibold M, 2008. Managing the aging workforce : status quo and implications for the advancement of theory and practice. European Management Journal, 26, 1-10.

Streb C, Gellert F J, 2011. What do we know about managing aging teams? Lessons learned from the automotive shop floor. Organizational Dynamics, 40, 144 - 150 . 
United States Bureau of Labor, 2016. Injuries, illnesses and fatalities.

http://www.bls.gov/iif.

Volkoff S, Buisset C, Mardon C, 2010. Does intense time pressure at work make older employees more vulnerable? A statistical analysis based on a French survey "SVP50". Applied Ergonomics, 41, 754-62.

World Health Organisation, 2015a. Ageing and health.

http://www.who.int/mediacentre/factsheets/fs404/en/ (accessed $4^{\text {th }}$ August 2016).

World Health Organisation, 2015b. World report on ageing and Health.

http://apps.who.int/iris/bitstream/10665/186463/1/9789240694811eng.pdf?ua=1 (accessed $4^{\text {th }}$ August 2016).

Yeatts D, Folts W, Knapp J, 2000. Older workers’ adaptation to a changing workplace : employment issues for the $21^{\text {st }}$ century. Educational Gerontology, 26, 565-582.

Ziekemeyer M, 2005. Age diverse management and a method for age proofing jobs. International Congress Series, 1280, 421-427. 
Table 1 Employer interviews: sector and number of employees represented.

\begin{tabular}{|c|c|c|c|c|}
\hline \multirow{2}{*}{ SECTOR } & \multicolumn{3}{|c|}{ Number of Employees } & \multirow{2}{*}{ TOTALS } \\
\hline & 10 to 49 & 50 to 249 & $250+$ & \\
\hline Manufacturing & 1 & 5 & 8 & 14 \\
\hline $\begin{array}{r}\text { Electricity, Gas, Steam \& Air } \\
\text { Conditioning } \\
\end{array}$ & 1 & & 4 & 5 \\
\hline Education & & 1 & 3 & 4 \\
\hline Wholesale \& Retail Trade & & & 3 & 3 \\
\hline Transport \& Storage & 1 & & 2 & 3 \\
\hline Human Health \& Social Work & & & 3 & 3 \\
\hline Professional, Scientific \& Technical & & & 2 & 2 \\
\hline Public Administration \& Defence & & & 2 & 2 \\
\hline Agriculture, Forestry, Fishing & & & 1 & 1 \\
\hline Mining \& Quarrying & & 1 & & 1 \\
\hline $\begin{array}{r}\text { Water, Sewerage \& Waste } \\
\text { Management }\end{array}$ & & 1 & & 1 \\
\hline Construction & & 1 & & 1 \\
\hline Arts, Entertainment \& Recreation & & & 1 & 1 \\
\hline TOTALS & 3 & 9 & 29 & 41 \\
\hline
\end{tabular}


Table 2 Composition of employee focus groups.

\begin{tabular}{|c|c|c|c|c|}
\hline $\begin{array}{c}\text { Group } \\
\text { No. }\end{array}$ & Participants & Gender & Sector & $\begin{array}{c}\text { Organisation } \\
\text { Size }\end{array}$ \\
\hline 1 & Managers/Office & $\begin{array}{c}6 \text { Male } \\
1 \text { Female }\end{array}$ & Manuf & Large \\
\hline 2 & Managers/Office & $\begin{array}{c}2 \text { Male } \\
2 \text { Female }\end{array}$ & Manuf & Large \\
\hline 3 & Managers/Operatives & 5 male & Manuf & Large \\
\hline 4 & Operatives & 3 Male & Manuf & Large \\
\hline 5 & Managers/Office & 4 Male & Manuf & Large \\
\hline 6 & Operatives & $\begin{array}{c}4 \text { Male } \\
1 \text { Female }\end{array}$ & Manuf & Large \\
\hline 7 & Operatives & 4 male & Manuf & Large \\
\hline 8 & Operatives & 4 Male & Manuf & Medium \\
\hline 9 & Operatives & 4 Male & Manuf & Medium \\
\hline 10 & Academics/Operatives & $\begin{array}{c}4 \text { male } \\
2 \text { Female }\end{array}$ & Educ & Large \\
\hline
\end{tabular}


Table 3 Focus group suggestions to help retain older workers.

\begin{tabular}{|l|}
\hline \multicolumn{1}{|c|}{ Focus group suggestions } \\
\hline Fairer/consistent actions/support \\
\hline Policy on age that is communicated to everyone \\
\hline Flexible working or job share \\
\hline Increase health checks and include capability questions during any \\
\hline Environmental improvements - lighting, flooring \\
\hline Age awareness training for managers \\
\hline Be able to access occupational health and advice discreetly \\
\hline Options to change jobs or work in different ways \\
\hline Change shift times or shift patterns \\
\hline More frequent breaks \\
\hline Recruit successor before person retires and remove headcount as a \\
company target \\
\hline Risk assessments should include person/equipment/job profiling \\
\hline Provide gym facilities \\
\hline Remove time pressures/work overload \\
\hline Have an age balanced workforce \\
\hline Job rotation \\
\hline Better rest facilities/quiet areas \\
\hline Hold discussion groups for older workers and seek their opinions \\
\hline
\end{tabular}

